\title{
PEMBERDAYAAN KADER KESEHATAN DALAM MENDETEKSI TANDA BAHAYA PADA KEHAMILAN, PERSALINAN DAN NIFAS
}

\section{EMPOWERMENT OF HEALTH CARDS IN DETECTING THE DANGER SIGNS OF PREGNANCY, CHILDBIRTH, AND POSTPARTUM PERIOD}

\author{
Santi Wahyuni*, Yanti Cahyati \\ Poltekkes Kemenkes Tasikmalaya \\ *Email: santiwahyuni@dosen.poltekkestasikmalaya.ac.id \\ (Diterima 18-01-2021; Disetujui 17-03-2021)
}

\begin{abstract}
ABSTRAK
Angka Kematian Ibu (AKI) di Indonesia hingga saat ini masih tinggi. Kematian ibu dapat terjadi pada masa kehamilan, persalinan maupun nifas. Kematian ibu di Indonesia dilatarbelakangi oleh 3 terlambat dan 4 terlalu. Salah satu faktor terlambat adalah keterlambatan di tingkat keluarga dalam mengenali tanda-tanda bahaya dalam kehamilan, persalinan dan nifas. Deteksi dini faktor risiko sangat diperlukan untuk menurunkan mortalitas dan morbiditas ibu dan janinnya. Di sinilah peran tenaga kesehatan, termasuk kader kesehatan dalam mendeteksi dini tanda bahaya. Kegiatan pengabdian ini bertujuan untuk meningkatkan kemampuan kader kesehatan dalam mendeteksi dini dan merujuk kasus kehamilan, persalinan dan nifas berisiko tinggi. Metode kegiatan menggunakan pelatihan, pendampingan dan penilaian kemampuan kader kesehatan dalam mendeteksi dini tanda bahaya.
\end{abstract}

Kata Kunci: deteksi dini, kader, tanda bahaya

\section{ABSTRACT}

Abstract: MMR in Indonesia is still high. Maternal death can occur during pregnancy, childbirth and childbirth. Maternal mortality in Indonesia is motivated by 3 late and 4 too. One factor late is a delay at the family level in recognizing danger signs in pregnancy, childbirth and the puerperium. Early detection of risk factors is needed to reduce maternal and fetal mortality and morbidity. This is where the role of health workers, including health cadres in early detection of danger signs. This service activity aims to improve the ability of health cadres to detect early and refer to high-risk cases of pregnancy, childbirth and the puerpurium. The method of activity uses training, mentoring and assessment of the ability of health cadres in early detection of danger signs.

Keywords: early detection, cadre, danger sign

\section{LATAR BELAKANG}

Kehamilan merupakan suatu fase dalam kehidupan wanita pada masa reproduksi dan termasuk proses yang alami dan fisiologis. Setiap ibu hamil menginginkan keselamatan baik bagi dirinya dan janin atau bayinya mulai dari proses kehamilan, persalinan sampai masa nifas. Sepanjang proses ini, ibu perlu beradaptasi terhadap berbagai perubahan baik fisik maupun psikis (Bobak, et al, 2004). Beberapa ibu, melalui proses dengan lancar, sesuai yang diharapkan. Namun, ada beberapa ibu mengalami masalah pada masa hamil, bersalin ataupun nifas. Keadaan ini tidak sama pada setiap ibu hamil dan setiap kehamilannya.

Proses kehamilan dan persalinan di Indonesia masih merupakan sesuatu yang berisiko dan dapat mengancam nyawa bagi ibu dan bayi. Hal ini ditunjukkan dengan 
tingginya Angka Kematian Ibu (AKI) dan Angka Kematian Bayi (AKB). Hasil Survei Penduduk Antar Sensus tahun 2015, AKI di Indonesia mencapai 305 per 100 ribu kelahiran hidup. Dalam 1 jam, Indonesia kehilangan 2 ibu dan 8 bayi baru lahir akibat kematian yang sebagian besar sebenarnya dapat dicegah (SUPAS, 2015). Menurut Data Profil Kesehatan Indonesia tahun 2019, AKI di Indonesia sebesar 205 per 100.000 Kelahiran Hidup. Berdasarkan data tersebut, terdapat 4.221 kematian ibu di Indonesia dengan tiga penyebab utama, yaitu perdarahan (1.280 kasus), hipertensi dalam kehamilan (1.066 kasus), dan infeksi (207 kasus).

Masalah kematian ibu tidak hanya disebabkan oleh penyebab langsung maupun tidak langsung. Penyebab lain berupa faktor-faktor non teknis seperti rendahnya status wanita, ketidakberdayaan dan taraf pendidikan yang rendah. Faktor lainnya yang mempengaruhi kesehatan wanita adalah kemiskinan, mahalnya biaya, keterbatasan jangkauan, terbatasnya akses untuk mendapatkan pelayanan kesehatan yang berkualitas dan rendahnya penelitian tentang kesehatan wanita. Termasuk pula budaya di masyarakat Indonesia, masih ada masyarakat yang melakukan praktik-praktik budaya yang membahayakan terhadap kehamilan, persalinan dan nifas (Suprabowo, 2006).

Upaya untuk mengatasi kendala berupa faktor non teknis, tidak selalu ditangani oleh sektor kesehatan karena sektor ini lebih terfokus pada intervensi untuk mengatasi penyebab kematian ibu secara langsung maupun tidak langsung. Berbagai sektor lain yang terkait dapat dilibatkan untuk mengatasi atau menangani masalah kesehatan yang berkaitan dengan kehamilan, persalinan dan nifas yang berisiko tinggi, salah satunya adalah melalui pemberdayaan kader kesehatan. Upaya pemberdayaan ini diwujudkan dengan meningkatkan peranan dan keterlibatan dari tenaga kesehatan maupun masyarakat. Pemberdayaan difokuskan pada upaya dalam mencegah keterlambatan pertama dari "tiga keterlambatan" yang melatarbelakangi kematian ibu, yaitu terlambat dalam mengenali tanda bahaya pada kehamilan, persalinan dan nifas di tingkat keluarga.

Deteksi dini oleh tenaga kesehatan dan masyarakat tentang adanya faktor risiko dan komplikasi, serta penanganan yang adekuat sedini mungkin, merupakan kunci keberhasilan dalam penurunan AKI dan AKB. Tanda bahaya kehamilan, persalinan dan nifas adalah tanda-tanda yang mengindikasikan adanya bahaya yang dapat terjadi selama masa kehamilan, persalinan dan nifas, yang apabila tidak dilaporkan atau terdeteksi bisa menyebabkan kematian ibu. Tanda bahaya kehamilan, persalinan dan nifas harus ditangani dan dideteksi sejak dini dengan benar karena setiap tanda bahaya kehamilan, persalinan 
dan nifas dapat mengakibatkan komplikasi pada masa hamil, persalinan dan masa nifas (Depkes RI, 2001).

Keluarga merupakan unit terkecil dalam masyarakat, seharusnya mampu mengenali keadaan kesehatan anggota keluarganya yang mengalami kehamilan, persalinan atau nifas. Keluarga perlu memiliki pengetahuan yang memadai tentang tanda bahaya kehamilan, persalinan dan nifas agar dapat melakukan identifikasi tanda bahaya dan mengantisipasi secara dini. Semakin baik pengetahuan ibu hamil tentang tanda-tanda bahaya kehamilan, persalinan dan nifas, maka ibu akan semakin mau memeriksakan kehamilannya secara teratur kepada petugas kesehatan selama periode kehamilannya (Sumarni, 2014). Pengetahuan yang tinggi menunjang terhadap perilaku yang tepat dalam perawatan kehamilan (Isdiaty dan Ungsianik, 2013).

Pemeriksaan kehamilan (ANC) penting dilakukan untuk memantau kesehatan ibu dan janin. Jumlah ANC berpengaruh terhadap pengetahuan ibu tentang tanda-tanda bahaya selama kehamilan. Ibu yang melakukan $\mathrm{ANC}>=4$ kali memiliki pengetahuan tentang tanda-tanda bahaya selama kehamilan 11 kali lebih baik daripada ibu yang hanya satu kali berkunjung. Ibu-ibu yang melahirkan anak di fasilitas pelayanan kesehatan, sekitar dua kali lebih berpengetahuan tentang tanda-tanda bahaya tenaga kerja daripada rekan-rekan mereka yang melahirkan di rumah (Bililign, N. \& Mulatu, T., 2017).

Selain ibu, suami sebagai pasangan dan pendamping ibu memiliki peranan yang sangat penting dalam upaya perlindungan kesehatan ibu dan anak-anaknya. Salah satu tugas suami sebagai kepala rumah tangga adalah pengambilan keputusan. Keputusan yang baik didukung oleh pengetahuan terhadap masalah (Depkes, 2001). Salah satu pengetahuan yang penting dimiliki oleh suami tentang kesehatan maternal dan neonatal yaitu mengetahui tanda bahaya pada masa kehamilan, persalinan, nifas dan neonatus dengan harapan dapat mencegah terjadi keterlambatan mengenal tanda bahaya gawat darurat serta mendapat pertolongan kesehatan yang memadai (Solihah, I., 2009).

Umumnya, masalah yang berkaitan dengan kehamilan dapat dideteksi secara dini, sehingga diperlukan kemampuan keluarga dalam mengenali tanda bahaya kehamilan, persalinan dan nifas. Terdeteksinya masalah atau gangguan pada kehamilan dapat ditindaklanjuti dengan upaya penanganan awal untuk mencegah terjadinya berbagai komplikasi kehamilan, persalinan maupun nifas.

Di RW 03 Kelurahan Bungur Besar sebagian besar yang mempengaruhi kesehatan perempuan adalah kasus kehamilan dengan risiko tinggi. Hasil studi pendahuluan menggunakan kuesioner diperoleh data bahwa kader kesehatan di wilayah RW 03 
seluruhnya (100\%) belum mendapatkan pelatihan mengenai deteksi dini kehamilan, persalinan dan nifas risiko tinggi. 90\% kader kesehatan berharap mendapatkan pengetahuan tentang pengenalan tanda bahaya pada kehamilan, persalinan dan nifas agar dapat memberikan penyuluhan kepada masyarakat, khususnya keluarga yang memiliki anggota keluarga yang hamil, bersalin ataupun nifas.

Salah satu peran kader kesehatan dalam mendeteksi dini kehamilan, persalinan dan nifas risiko tinggi adalah melalui pemberian penyuluhan kesehatan mengenai pengenalan tanda bahaya pada kehamilan, persalinan dan nifas agar masyarakat mendapat wawasan dan termotivasi melaksanakan terapi atau penanganan lebih lanjut. Upaya peningkatan peran dan fungsi kader di atas, perlu mendapatkan dukungan dalam wujud pembekalan kader kesehatan yaitu pelatihan kader yang berkaitan dengan kehamilan, persalinan dan nifas yang berisiko tinggi.

\section{BAHAN DAN METODE}

Metode yang digunakan untuk mendukung pelaksanaan pengabdian kepada masyarakat adalah sebagai berikut :

1. Kegiatan Pengkajian

Pengkajian di lapangan menggunakan pendekatan model Precede. Data dikumpulkan dengan menggunakan metode wawancara, observasi, studi dokumentasi dan pengisian kuesioner. Berdasarkan temuan masalah di lapangan, kemudian disusun rencana kegiatan pelatihan bagi kader kesehatan tentang tanda bahaya pada kehamilan, persalinan dan nifas.

2. Kegiatan Persiapan

Kegiatan persiapan meliputi identifikasi peserta pelatihan kader, koordinasi waktu dan tempat pelatihan kader, penyusunan proposal pelatihan, penyusunan materi pelatihan kader, penyusunan tools (instrumen) penilaian tanda bahaya pada kehamilan, persalinan dan nifas, penyusunan media pembelajaran untuk kader kesehatan (peserta pelatihan) dan untuk ibu/keluarga (sebagai sasaran kegiatan) serta penyusunan instrumen evaluasi.

3. Kegiatan pelaksanaan

Pelatihan kader kesehatan diawali dengan pre-test untuk mengukur pengetahuan awal yang dimiliki oleh kader kesehatan, dilanjutkan penyampaian materi pelatihan, diskusi, tanya jawab, demonstrasi cara memberikan penyuluhan kesehatan, cara menilai atau mendeteksi dini risiko pada kehamilan, persalinan dan nifas, serta cara melakukan rujukan pada kasus kehamilan, persalinan ataupun nifas yang berisiko. 
4. Kegiatan evaluasi

Evaluasi post-test dilakukan setelah kegiatan penyampaian materi dan praktik/ demonstrasi. Selain evaluasi pengetahuan kader tentang tanda bahaya pada kehamilan, persalinan dan nifas, juga evaluasi kemampuan kader dalam memberikan penyuluhan tentang tanda bahaya pada kehamilan, persalinan dan nifas terhadap ibu-ibu di wilayah RW 03. Selanjutnya, dilakukan observasi kemampuan kader dalam menilai keadaan kehamilan, persalinan dan nifas serta melakukan rujukan bagi ibu hamil, ibu bersalin atau ibu nifas yang berisiko tinggi.

\section{HASIL DAN PEMBAHASAN}

Pelaksanaan kegiatan pelatihan kader kesehatan bertempat di aula Kelurahan Bungur Besar. Pelatihan dibuka oleh lurah Bungur Besar diikuti oleh kepala Puskesmas Kelurahan Bungur Besar dan staf Puskesmas Kelurahan Bungur Besar. Jumlah peserta pelatihan 43 orang, terdiri atas para kader kesehatan dari RW 1 sampai RW 10 dan ketua penggerak PKK Kelurahan Bungur Besar.

Setelah acara pembukaan pelatihan kader kesehatan, peserta mengikuti kegiatan pretest untuk mengukur pengetahuan awal sebelum materi pelatihan diberikan. Selanjutnya, pemberian materi pelatihan kader kesehatan tentang pengenalan tanda bahaya pada kehamilan, persalinan dan nifas serta materi sistem rujukan bagi ibu hamil. Peserta pelatihan mendapatkan kit pelatihan yang berisi buku pedoman bagi kader kesehatan dan dilengkapi leaflet ditujukan untuk memudahkan para kader dalam memberikan penyuluhan kesehatan pada keluarga di wilayahnya yang mempunyai ibu hamil, ibu bersalin dan ibu nifas. Kegiatan pelatihan kader kesehatan terlihat pada Gambar 1.

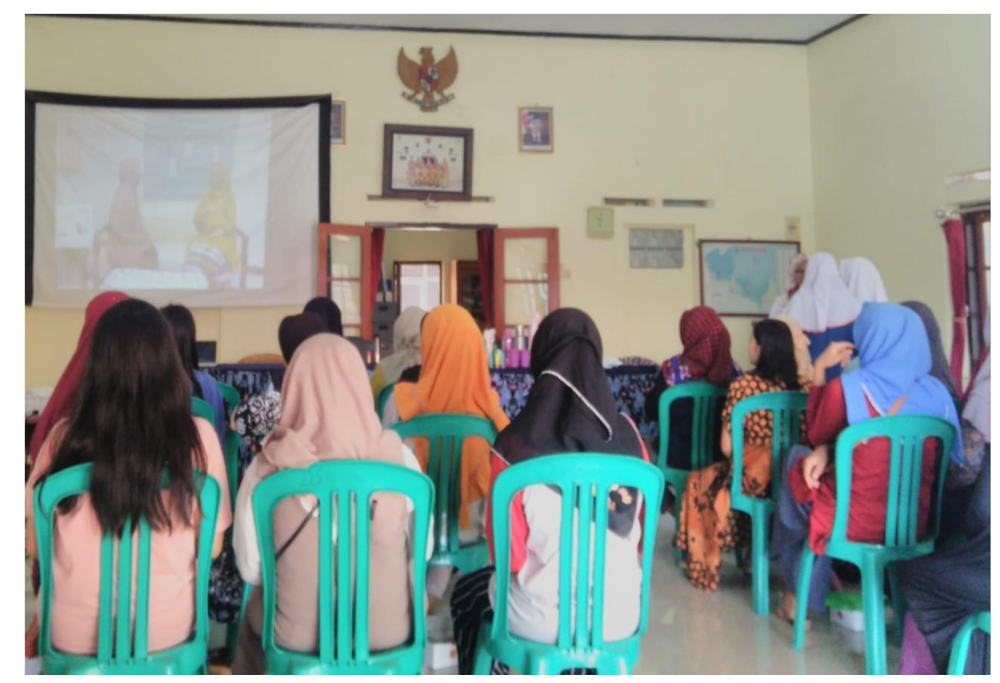

Gambar 1. Pelatihan kader kesehatan 
Selain materi yang berupa teori, peserta mengikuti kegiatan praktik yaitu demonstrasi (peragaan cara pengukuran LILA) dan cara menggunakan tools (instrumen) untuk menilai kehamilan, persalinan dan nifas berisiko. Selanjutnya, para kader dihimbau untuk menindaklanjuti penemuan tanda bahaya pada kasus ibu hamil, ibu bersalin dan ibu nifas untuk dirujuk sesuai dengan materi sistem rujukan yang telah disampaikan.

Selama kegiatan tanya jawab, tampak peserta pelatihan kader sangat antusias mengajukan berbagai pertanyaan, bahkan di luar sesion tanya jawab (setelah pelatihan ditutup), masih ada beberapa peserta pelatihan yang ingin bertanya, berkonsultasi mengenai kehamilan dan kesehatan perempuan. Evaluasi kedua untuk mengetahui tingkat pengetahuan peserta setelah mendapatkan materi pelatihan, dilakukan melalui post-test. Kegiatan pelatihan diakhiri dengan acara pembagian doorprize dan penutupan, seperti yang terlihat pada Gambar 2.

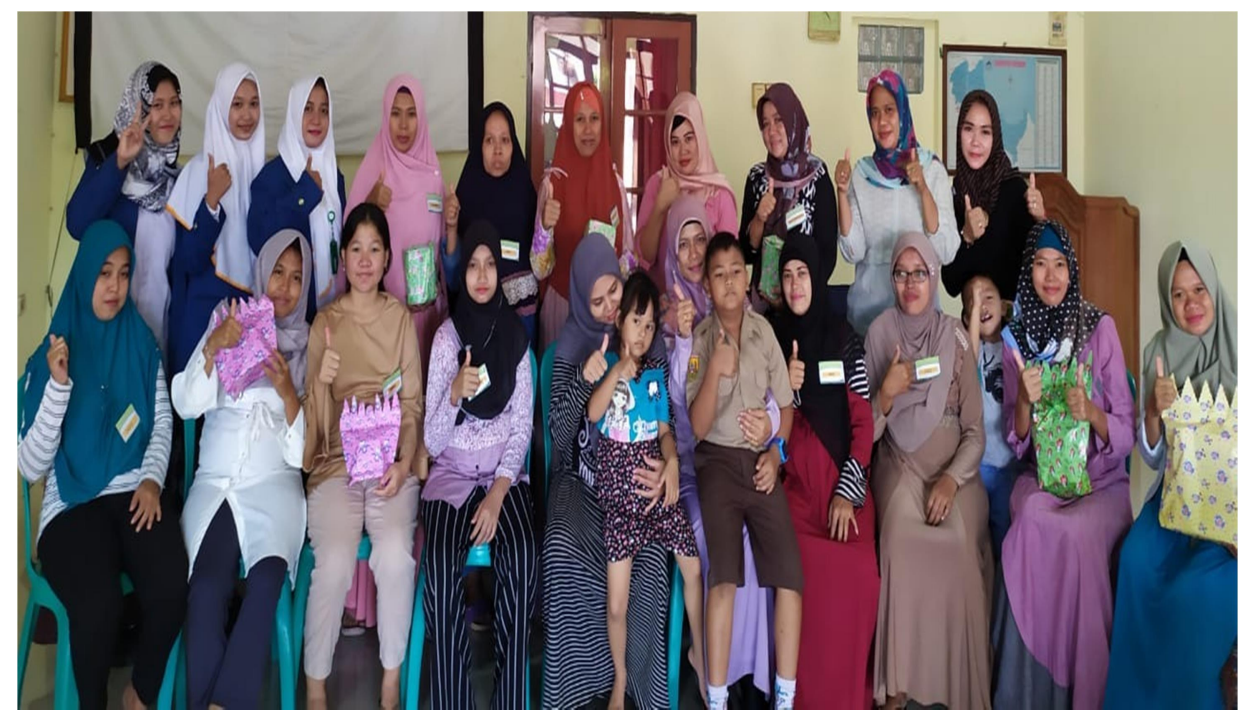

Gambar 2. Pembagian doorprize bagi peserta

Adapun evaluasi hasil pelaksanaan pelatihan kader kesehatan tentang pengenalan tanda bahaya pada kehamilan, persalinan dan nifas sebagai berikut:

1. Meningkatnya pengetahuan kader kesehatan tentang pengenalan tanda bahaya pada kehamilan, persalinan dan nifas (100\% meningkat saat post-test) terlihat dari perubahan nilai pre-test dan post test. Nilai rata-rata pre-test 45 , nilai terendah 10 , nilai tertinggi 80 , sedangkan nilai rata-rata post-test 82 , nilai terendah 60 , nilai tertinggi 100 .

2. Semua kader kesehatan sebagai peserta pelatihan mengikuti acara sampai selesai dan para kader termasuk aktif mengajukan berbagai pertanyaan terkait masalah kehamilan, persalinan dan nifas; baik berdasarkan pengalaman pribadi, tetangga atau kerabat lainnya. 
Setelah kegiatan pelatihan di atas, rangkaian kegiatan pengabdian masyarakat ini dilanjutkan dengan pendampingan pemberian penyuluhan kesehatan tentang pengenalan tanda bahaya pada kehamilan, persalinan dan nifas, dan kegiatan pendampingan pencarian keluarga yang memiliki anggota keluarga dengan ibu hamil, bersalin dan nifas risiko tinggi. Selama masa pendampingan pemberian penyuluhan kesehatan, dilakukan pula kegiatan pendampingan untuk proses rujukan yaitu merujuk ibu yang terdeteksi berisiko tinggi pada kehamilan, persalinan dan nifas. Kegiatan lainnya adalah melakukan diskusi bersama kader kesehatan dan petugas Puskesmas Bungur Besar mengenai hasil temuan kasus kehamilan, persalinan dan nifas berisiko tinggi.

Evaluasi dari kegiatan pendampingan pemberian penyuluhan kesehatan tentang tanda bahaya pada kehamilan, persalinan dan nifas oleh kader kesehatan dilakukan pada 16 ibu hamil. Selanjutnya, dilakukan penilaian keadaan kehamilan, persalinan dan nifas berdasarkan format (tools) pengkajian. Kader juga berupaya untuk merujuk ibu yang terdeteksi memiliki tanda bahaya/faktor risiko. Pelaksanaan kegiatan ini lebih bersifat door to door yaitu dengan cara mendatangi satu per satu ibu hamil. Ibu hamil dan keluarganya mendapatkan wawasan dan pengetahuan tentang kehamilannya, dan mengetahui kondisi kehamilannya (kategori berisiko atau tidak berisiko). Kegiatan pendampingan seperti yang ditunjukkan pada Gambar 3.

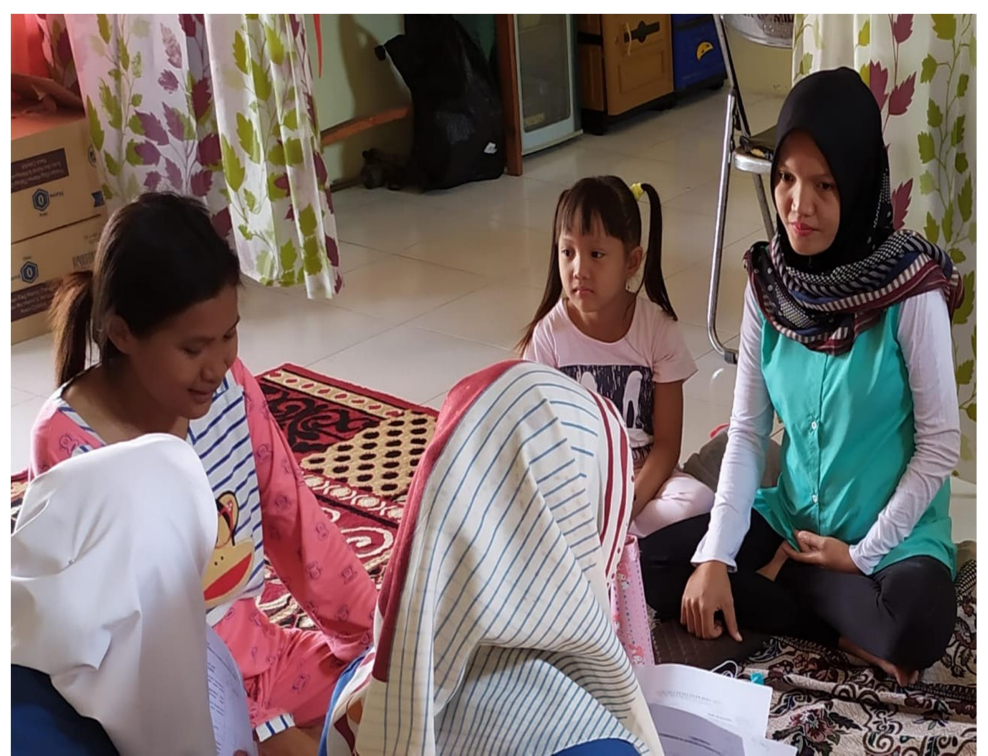

Gambar 3. Pendampingan penyuluhan kesehatan dan deteksi dini

Hasil pendeteksian atau penilaian kehamilan, persalinan dan nifas dapat diuraikan dengan Tabel 1. 
Tabel 1. Rekapan Penilaian Kehamilan, Persalinan dan Nifas Berisiko Tinggi

\begin{tabular}{|c|c|c|c|c|}
\hline No. & $\begin{array}{l}\text { Nama, } \\
\text { Usia }\end{array}$ & Data Yang Ditemukan & Kesimpulan & Tindakan \\
\hline 1. & $\begin{array}{l}\text { Ny. Y } \\
40 \text { tahun }\end{array}$ & $\begin{array}{l}\text { Ibu hamil } 12 \text { minggu } \\
\text { - Usia }>35 \text { tahun } \\
\text { - Jumlah anak }>4 \text { orang }\end{array}$ & Risiko tinggi & $\begin{array}{l}\text { ANC (+) : tidak perlu } \\
\text { dirujuk }\end{array}$ \\
\hline 2. & $\begin{array}{l}\text { Ny. F } \\
23 \text { tahun }\end{array}$ & Ibu nifas 10 hari, ASI $(+)$, tidak demam & $\begin{array}{l}\text { Tidak } \\
\text { berisiko }\end{array}$ & - \\
\hline 3. & $\begin{array}{l}\text { Ny. D } \\
28 \text { tahun }\end{array}$ & $\begin{array}{l}\text { Ibu hamil } 32 \text { minggu } \\
\text { - Bengkak pada tangan } \\
\text { - Pusing }(+) \\
\text { - Peningkatan BB berlebih }\end{array}$ & Risiko tinggi & $\begin{array}{l}\text { ANC }(+) \text { di dr obgin : } \\
\text { tidak perlu dirujuk }\end{array}$ \\
\hline 4. & $\begin{array}{l}\text { Ny. I } \\
23 \text { tahun }\end{array}$ & $\begin{array}{l}\text { Ibu hamil } 12 \text { minggu } \\
\text { - Jarak kehamilan }<2 \text { tahun } \\
\text { - Hipertensi }\end{array}$ & Risiko tinggi & $\begin{array}{l}\text { Rujuk ke Puskesmas } \\
\text { Bungur }\end{array}$ \\
\hline 5. & $\begin{array}{l}\text { Ny. E } \\
38 \text { tahun }\end{array}$ & $\begin{array}{l}\text { Ibu hamil } 16 \text { minggu } \\
\text { - Usia }>35 \text { tahun }\end{array}$ & Risiko tinggi & $\begin{array}{l}\text { ANC (+) di bidan : tidak } \\
\text { perlu dirujuk }\end{array}$ \\
\hline 6. & $\begin{array}{l}\text { Ny. K } \\
23 \text { tahun }\end{array}$ & Ibu hamil 24 minggu & $\begin{array}{l}\text { Tidak } \\
\text { berisiko }\end{array}$ & - \\
\hline 7. & $\begin{array}{l}\text { Ny. R } \\
18 \text { tahun }\end{array}$ & $\begin{array}{l}\text { Ibu hamil } 12 \text { minggu } \\
\text { - BB tidak naik } \\
\text { - LILA }<23,5 \mathrm{~cm} \\
\text { - Jarak kehamilan }<2 \text { tahun } \\
\text { - Usia }<20 \text { tahun }\end{array}$ & Risiko tinggi & $\begin{array}{l}\text { Rujuk ke Puskesmas } \\
\text { Bungur }\end{array}$ \\
\hline 8. & $\begin{array}{l}\text { Ny. S } \\
22 \text { tahun }\end{array}$ & $\begin{array}{l}\text { Ibu hamil 35-36 minggu } \\
\text { - Keluar lendir dan darah } \\
\text { - Flour albus }(+) \\
\text { - Kehamilan ke-4 } \\
\text { - Jarak kehamilan }<2 \text { tahun }\end{array}$ & Risiko tinggi & $\begin{array}{l}\text { ANC (+) di Puskesmas } \\
\text { Senen, sudah dirujuk ke } \\
\text { RSCM }\end{array}$ \\
\hline 9. & $\begin{array}{l}\text { Ny. Sd } \\
39 \text { tahun }\end{array}$ & $\begin{array}{l}\text { Ibu hamil 25-26 minggu } \\
\text { - Ibu tidak mau makan dan muntah terus } \\
\text { - Usia }>35 \text { tahun } \\
\text { - Kehamilan ke-4 } \\
\text { - Riwayat DM }\end{array}$ & Risiko tinggi & $\begin{array}{l}\text { Rujuk ke Puskesmas } \\
\text { Senen }\end{array}$ \\
\hline 10. & $\begin{array}{l}\text { Ny. Ro } \\
31 \text { tahun }\end{array}$ & $\begin{array}{l}\text { Ibu hamil 35-36 minggu } \\
\text { Berat badan tidak naik }\end{array}$ & Risiko tinggi & $\begin{array}{l}\text { ANC (+) di Puskesmas } \\
\text { Senen : tidak perlu dirujuk }\end{array}$ \\
\hline 11. & $\begin{array}{l}\text { Ny. Ri } \\
21 \text { tahun }\end{array}$ & Ibu hamil 20-21 minggu & $\begin{array}{l}\text { Tidak } \\
\text { berisiko }\end{array}$ & - \\
\hline 12. & $\begin{array}{l}\text { Ny. L } \\
23 \text { tahun }\end{array}$ & Ibu hamil 20-21 minggu & $\begin{array}{l}\text { Tidak } \\
\text { berisiko }\end{array}$ & - \\
\hline 13. & $\begin{array}{l}\text { Ny. T } \\
37 \text { tahun }\end{array}$ & $\begin{array}{l}\text { Ibu hamil } 34 \text { minggu } \\
\text { - Usia }>35 \text { tahun } \\
\text { - Riwayat DM }\end{array}$ & Risiko tinggi & $\begin{array}{l}\text { ANC (+) di dokter obgin : } \\
\text { tidak perlu dirujuk }\end{array}$ \\
\hline 14. & $\begin{array}{l}\text { Ny. } \mathrm{N} \\
44 \text { tahun }\end{array}$ & $\begin{array}{l}\text { Ibu hamil } 24 \text { minggu } \\
\text { - Usia }>35 \text { tahun }\end{array}$ & Risiko tinggi & $\begin{array}{l}\text { ANC (+) di bidan : tidak } \\
\text { perlu dirujuk }\end{array}$ \\
\hline 15. & $\begin{array}{l}\text { Ny. Rd } \\
38 \text { tahun }\end{array}$ & $\begin{array}{l}\text { Ibu hamil } 38 \text { mg (aterm) } \\
\text { - Usia }>35 \text { tahun } \\
\text { - Jumlah anak }>4 \text { orang } \\
\text { - Jarak anak }<2 \text { tahun } \\
\text { - Letak janin : melintang } \\
\text { - Riwayat anak lahir prematur }\end{array}$ & Risiko tinggi & $\begin{array}{l}\text { ANC (+) di dokter obgin } \\
(\mathrm{RSCM})\end{array}$ \\
\hline 16. & $\begin{array}{l}\text { Ny. K } \\
26 \text { tahun }\end{array}$ & Ibu hamil 15 minggu & $\begin{array}{l}\text { Tidak } \\
\text { berisiko }\end{array}$ & - \\
\hline 17. & $\begin{array}{l}\text { Ny. Y } \\
36 \text { tahun }\end{array}$ & $\begin{array}{l}\text { Ibu hamil } 12 \text { minggu } \\
\text { - Usia }>37 \text { tahun } \\
\text { - } \text { LILA }=23,4 \mathrm{~cm} \\
\end{array}$ & Risiko tinggi & $\begin{array}{l}\text { Rujuk ke Puskesmas } \\
\text { Bungur }\end{array}$ \\
\hline
\end{tabular}


Berdasarkan data Tabel 1, diketahui bahwa ibu hamil yang berisiko tinggi sebanyak 12 orang $(75 \%)$ dan yang tidak berisiko 4 orang (25\%). Dari kedua belas ibu hamil tersebut, sebagian besar ( 8 orang) sudah melakukan ANC secara teratur, baik di klinik dokter spesialis kandungan, bidan praktik swasta maupun di institusi pelayanan kesehatan seperti puskesmas ataupun rumah sakit. Delapan orang tersebut tidak perlu dirujuk lagi. Selebihnya, yaitu 4 orang perlu dirujuk baik untuk pemeriksaan kehamilan di Puskesmas Kelurahan Bungur Besar ataupun Puskesmas Kecamatan Senen. Ibu nifas yang ditemukan 1 orang dan termasuk kategori normal atau tidak berisiko.

\section{KESIMPULAN DAN SARAN}

Kegiatan pengabdian kepada masyarakat ini mendapat sambutan, tanggapan dan perhatian yang baik dari berbagai pihak, diantaranya puskesmas Senen, puskesmas Bungur, pejabat kelurahan Bungur serta masyarakat setempat. Kegiatan pelatihan ini dapat meningkatkan pengetahuan kader tentang pengenalan tanda bahaya pada kehamilan, persalinan dan nifas. Kegiatan pendampingan dapat meningkatkan kemampuan kader dalam memberikan penyuluhan, menilai kondisi kesehatan dan merujuk ibu hamil yang berisiko. Pengetahuan dan keterampilan yang memadai menunjang terhadap peningkatan peran kader kesehatan di masyarakat.

Saran bagi puskesmas untuk melanjutkan pembinaan dan memonitor para kader kesehatan dalam mendeteksi kasus keluarga dengan ibu hamil, ibu bersalin dan ibu nifas berisiko tinggi, menindaklanjuti penemuan kasus kehamilan, persalinan dan nifas berisiko dengan memfasilitasi proses rujukan. Saran bagi kader kesehatan untuk menindaklanjuti kegiatan penyuluhan tentang pengenalan tanda bahaya pada persalinan, kehamilan dan nifas, melakukan penilaian dan merujuk kasus risiko tinggi, serta mengembangkan diri dengan menambah pengetahuan melalui membaca dan mengikuti berbagai pelatihan tentang kesehatan, baik ibu dan anak sehingga informasi yang diberikan lebih berkualitas.

\section{UCAPAN TERIMA KASIH}

Ucapan terima kasih kami sampaikan kepada semua pihak yang telah membantu pelaksanaan kegiatan pengabdian kepada masyarakat ini, yaitu Kepala Puskesmas Senen, Kepala Puskesmas Bungur, Kepala Kelurahan Bungur, staf dan jajarannya serta masyarakat setempat atas perhatian dan kerjasamanya sehingga kami dapat melaksanakan rangkaian kegiatan pengabdian kepada masyarakat, dan semua pihak yang telah membantu dalam pelaksanaan kegiatan ini yang tidak dapat kami sebutkan satu per satu. 


\section{DAFTAR PUSTAKA}

Bobak, Lowdermilk, Jensen. (2004). Buku Ajar Keperawatan Maternitas / Maternity Nursing. (Edisi 4), Alih Bahasa Maria A. Wijayati, Peter I. Anugerah, Jakarta: EGC.

Departemen Kesehatan RI. (2001). Buku Pedoman Pengendalian Tanda Bahaya pada Kehamilan, Persalinan, dan Nifas. Jakarta. Departemen Kesehatan R.I.

Kemenkes R.I. (2014). Peraturan Menteri Kesehatan Republik Indonesia Nomor 97 Tahun 2014 tentang Pelayanan Kesehatan Masa Sebelum Hamil, Masa Hamil, Persalinan, dan Masa Sesudah Melahirkan, Penyelenggaraan Pelayanan Kontrasepsi, Serta Pelayanan Kesehatan Seksual. Jakarta.

Kemenkes R.I. (2019). Profil Kesehatan Indonesia 2019. https://pusdatin.kemkes. go.id/resources/download/pusdatin/profil-kesehatan-indonesia/profil-kesehatanindonesia-2019.pdf\&ved (Diakses pada tanggal 7 Februari 2021)

Isdiaty, F.N., Ungsianik, T. (2013). Pengetahuan Tanda Bahaya Kehamilan dan Perilaku Perawatan Kehamilan pada Ibu Hamil Trimester III. Jurnal Keperawatan Indonesia, 16 (1), h. 18-24

Bililign, N. \& Mulatu, T. (2017). Knowledge of obstetric danger signs and associated factors among reproductive age women in Raya Kobo district of Ethiopia: A community based cross-sectional study. Bio Medical Central : Pregnancy and Childbirth. 17 (70), p. 1-7.

Sholihah I. (2009). Faktor-faktor yang berhubungan dengan Pengetahuan Suami tentang Tanda Bahaya pada Masa Kehamilan, Persalinan, Nifas dan Neonatus di Kabupaten Garut Jawa Barat. Media Litbang Kesehatan, 19 (2), h. 89-100.

Sumarni. (2014). Hubungan Pengetahuan dan Sikap Ibu Hamil terhadap Perilaku ANC. Jurnal Media Kesehatan Masyarakat Indonesia : FKM, The Indonesian Journal of Public Health, 10 (4), h. 200-204.

SUPAS BPS. (2015). Profil Penduduk Indonesia Hasil SUPAS 2015.

Suprabowo, E., (2006). Praktik Budaya dalam Kehamilan, Persalinan dan Nifas pada Suku Dayak Sanggau. Jurnal Pendidikan Kesehatan Ilmu Perilaku, h. 112-121. 